\title{
General View of Instrumentation in Japanese Iron and Steel Industry
}

(Report of research activities of Instrumentation Division of Steel Technology Joint Research Society)

By Kosuke Kikuchi

Chairman of Instrumentation Division

\section{Foreword}

The Steel Technology Joint Research Society, an organization conducting joint research covering all aspects of iron and steel making techniques, is divided into several research divisions. Research activities have been conducted by members selected respectively from engineers of iron and steel companies, governmental organizations and scientists of universities.

This report treats mainly the development of research activities in the Instrumentation Division with reference to the outline of the development of instrumentation and automatic control in Japan and recent main topics concerned.

\section{Development of Research Activities of the Instrumentation Division}

The origin of the Instrumentation Division goes back to the Heat Instruments Special Committee of the Heat Economy Technique Division established in 1949 with a view to strengthening heat economy. Committee meetings were held twentyone times up to 1955 , where standard instrumentation of iron and steel making equipment, standardization of maintenance, of inspections and repairing of industrial instruments were subjects of discussion. The result of this research was published in 1953 in the form of a "Handbook of Heat Economy Technique: Instrumentation." This book was well received by engineers in this field as a good guide which effectively utilized the experience of plant engineers engaged in technical practice.

With the establishment of the Steel Technology Joint Research Society in 1955, this Heat Instruments Special Committee made a new start as the Instrumentation Subcommittee of the Heat Economy Technique Division. For the five years since then research on the problems of instrumental control in the iron and steel industry has been carried out. During this period, seven committee meetings were held and the number of reports presented to the committees amounted to 406 . "Handbook of Electronic Instruments" and "Automatic Control of Open Hearth Furnaces" were published respectively in 1957 and 1959. In the summer of 1959 a Weighing Subcommittee was established for the purpose of doing research on the problems of weighing.

With the development of activities of the Instrumentation Subcommittee, its research field extended beyond the limits of heat economy technique. Developmental research on the technique of instrumentation and control covering the entire field of iron- and steel-making technique such as quality control, metallurgical control and process control has been requested.

Accordingly, the Instrumentation Subcommittee was separated from the Heat Economy Technique Division at the end of 1960 and has taken an independent form as the Instrumentation Division. The Weighing Subcommittee was considered to belong to this Division. As stated above, the Instrumentation Division has been active for a total period of twelve years. It has laid the foundation for making further development as a new Division and much activity in the future is expected from it.

\section{Change and Present State of Instrumenta- tion Technique in Iron and Steel Industry}

When plant operation showed a gradual improvement with the gradual restoration of the iron and steel industry after World War II, strengthening of heat control was advocated, and flowmeters, pyrometers and pressuremeters were first equipped to heating furnaces in the rolling mill. Before the war, there were some kinds of meters, but almost all of them being primitive, it is not too much to say that a technique worthy to be called "instrumentation" first began to find its way into plant operation at that time.

Heating furnaces equipped with meters in rolling mills not only contributed much to the promotion of heat control, but also presented fundamental measured data to heat balance which gained popularity at the time and was effective for the saving of fuel. The object of this instrumentation came to cover a wide field, from heating furnaces to open hearth furnaces, converters, boilers, blast furnaces, coke ovens, and hot blast stoves. Instruments have also been used for the supplydemand operation of coke oven gas, blast furnace gas, blast air for blast furnaces, and plant water and sea water for industrial use. The application of automatic control equipment has become active year by year and this has brought about great strides in instrumentation technique.

With the gradual increase of kinds and number of instruments, many steel companies, in view of facilitating the application of these instruments, have formed a special organization for their maintenance, fully provided testing and inspection equipment, promoted testing and research organizations, and devised and perfected planning.

You will note the rapid progress in Fig. 1 which shows the change in the number of industrial instruments used and of workers engaged in maintaining them at a certain works. 


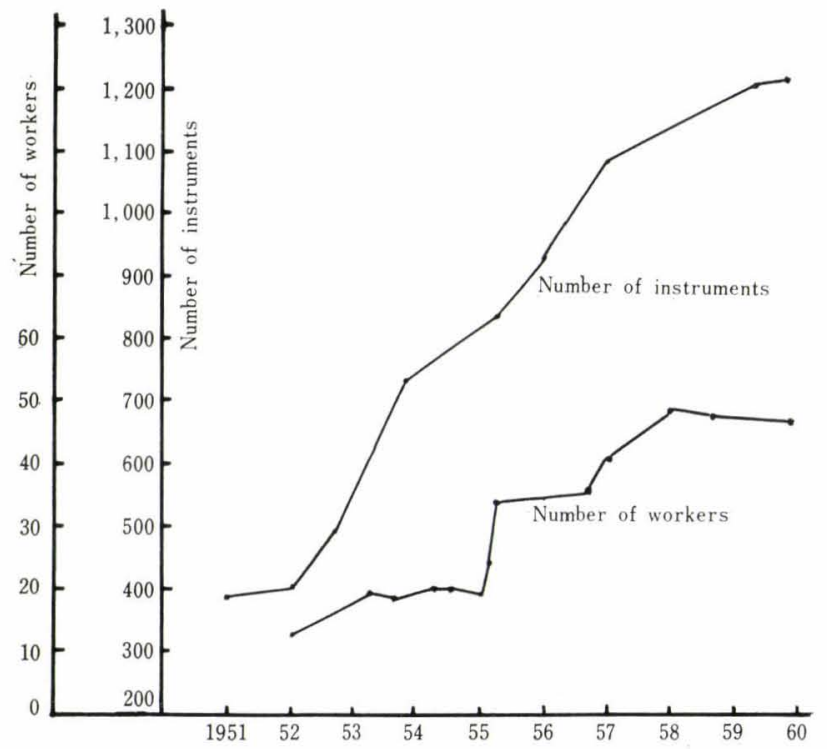

Fig. 1 Change in the number of instruments and workers concerned

During the period when technique of instrumentation in the iron and steel industry has shown remarkable development, active discussions have been held on various subjects in the Instrumentation Division. The subjects of discussion have ranged from the development of new techniques to trifling problems on maintenance operation. Some subjects of talks in which each member of the committee is interested are enumerated as follows.

\section{In the Field of Pig Iron Making:}

(1) Instrumentation and control of distribution of blast flow fed to blast furnace tuyeres.

(2) Control of humidity in the blast to blast furnaces.

(3) Continuous analysis of blast furnace gas.

(4) Continuous measurement of the temperature of tapped molten iron.

(5) Problems of centralized control.

(6) Analysis of points which have coms to the front in weighing.

(7) Gas calorimeter and automatic control.

(8) Other new instrumentation techniques for blast furnaces, hot blast stoves and sintering plants.

In the Field of Steelmaking:

(1) Automatic control of open hearth furnaces.

(2) Measurement of molten bath temperature by use of an immersion pyrometer.

(3) Continuous analysis of waste gas.

In the Field of Rolling Mills:

(1) Automatic control of soaking pits and bloom heating furnaces.

(2) Method of measuring temperatures of blooms and materials to be rolled.
(3) Instrumentation of heat-treating furnaces.

(4) Apparatus for continuous measurement of the thickness and width of steel products.

For the items mentioned above, it is understood that most of the subjects are those concerning heat. Of late, however, instrumentation shows a tendency to find its way into the fields of quality control and metallurgical control, and the following items have been introduced:

(a) Apparatus for mcasuring quantity of the tin stuck to sheets by fluorescent X-ray analysis. (Quantrol)

(b) Penetrating a hot bloom by using a Betatron and visualizing it by using an image intensifier and by television.

(c) Pinhole detector for the sheet in the shearing process in cold strip mills.

(d) Photoelectric width gauge for hot strip.

(e) Wire-rod dimension gauge.

(f) Infrared width gauge.

As new trends in instrumentation technique realize, many steel companies are now taking much interest in centralized control, application of data logger and computing control by an electronic computer. These shall be mentioned later.

With the development of new techniques as mentioned above, problems on the maintenance of instruments must not be forgotten. Each steel company is now confronted with difficult problems on the maintenance of instruments as follows:

(1) New instruments have been successively developed and introduced, but teaching and training of workers concerned do not keep pace with it.

(2) It cannot be easily decided whether an instrument is operating correctly and so a special testing technique is required.

(3) Comparatively frequent Instrument disorders require much time in maintenance.

The fact that the Instrumentation Division consists mainly of members engaged in practice in iron and steel companies and that many concrete problems on maintenance have been deliberated is presumably a special feature different from that characterizing other research organizations. It must be said, nevertheless, that there remain many unsolved problems. Main subjects hitherto discussed in the Division are as follows:

\section{Automatic Control of Open Hearth Furnaces}

Automatic control of open hearth furnaces has been one of the main subjects in the Instrumentation Division. Thanks to the earnest efforts and cooperation of each member, reports presented to the Division amounted to about 200. These reports were classified and rearranged in the subcommittee 
established for this purpose and published in 1959 in the form of a book entitled "Automatic Control of Open Hearth Furnace."

In respect to automatic control of open hearth furnaces, simple explanation shall be given herein:

Fig. 2 shows an open hearth furnace in which heavy oil is used as fuel, steam as an atomizer, air and oxygen for combustion. An automatic control system consists of apparatus for controlling pressure within the furnace, roof temperature, combustion, flow of steam and oxygen, temperature of heavy oil, and automatic reversal of regenerators and burners.

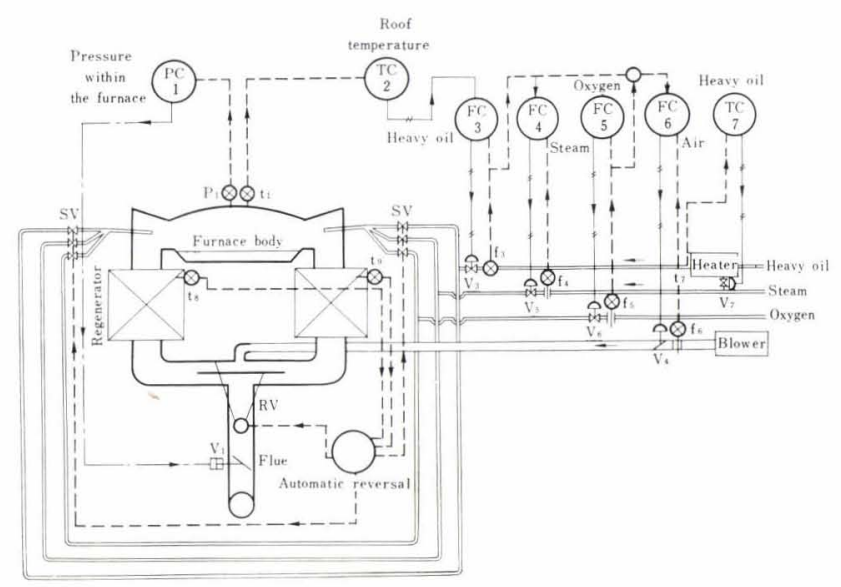

Fig. 2 Flow diagram showing automatic control of an O.H. furnace

\section{Control of Pressure within the Furnace}

This apparatus aims at stabilizing atmosphere within the furnace by making pressure within it uniform and preventing flow of air into the furnace and flame overflow out of the furnace. In Fig. 2 PC-1 shows its controller.

\section{Control of Roof Temperature}

This apparatus aims primarily at controlling molten bath temperature. But direct measurement of it being difficult, it controls inflow of fuel in order to keep the temperature of roof refractories of the furnace constant. In the figures, TC-2 and FC-3 show respectively a temperature controller and a heavy-oil flow controller.

\section{Control of Steam (or Primary Air)}

This apparatus aims at controlling automatically the flow or the pressure of steam (or primary air). It is used as an atomizer in order to keep the atomizing of heavy oil always in good condition. In the figure, steam-flow controller $\mathrm{FC}-4$ receives a signal of heavy-oil flow and controls steam flow so as to be proportional to it.

\section{Control of Oxygen}

This apparatus aims at controlling flow and pressure of oxygen in order to keep proper use of it for supporting combustion, and for bessemerizing. FC-5 shows an oxygen flow controller.

\section{Control of Combustion}

This apparatus aims at keeping combustion under rational conditions by keeping the air quantity for combustion at a fixed rate to the fuel supplying quantity. FC-6 shows an air flow controller.

\section{Control of Heavy-Oil Temperature}

TC-7 shows a controller of heavy-oil temperature.

\section{Automatic Reversal of Regenerators and Burners}

This apparatus aims at making preheating of air for combustion effective by practising reversal of both regenerators and burners in good order at the proper time.

The above mentioned describes the automatic control of open hearth furnaces. Automatic control equipment fitted to open hearth furnaces in the main iron and steel works of Japan is so numerous that the automatic control system has come into wide use to such an extent that almost all open hearth furnaces have been equipped with it.

Adoption of automatic control has brought many improvements into open hearth furnace operation. Not to mention stabilization and improvement in operation, automatic control has contributed much to the decrease in fuel consumption, improvement in efficiency in steelmaking, stabilization of steel quality and prolongation of furnace life. Fig. 3 and Fig. 4 show respectively actual results in a certain open hearth furnace and general tendency in Japan.
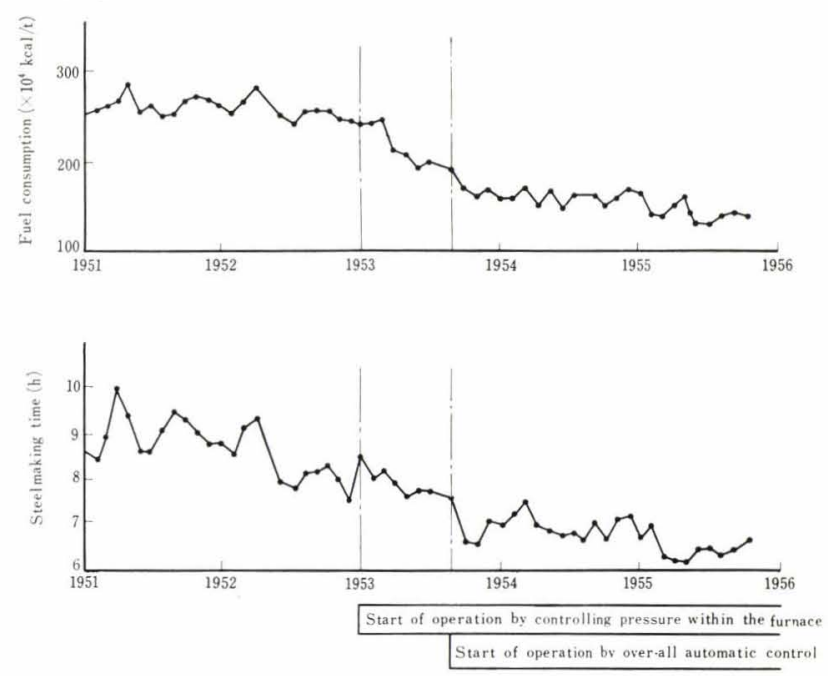

Fig. 3 Results of automatic control of a certain O.H. furnace 


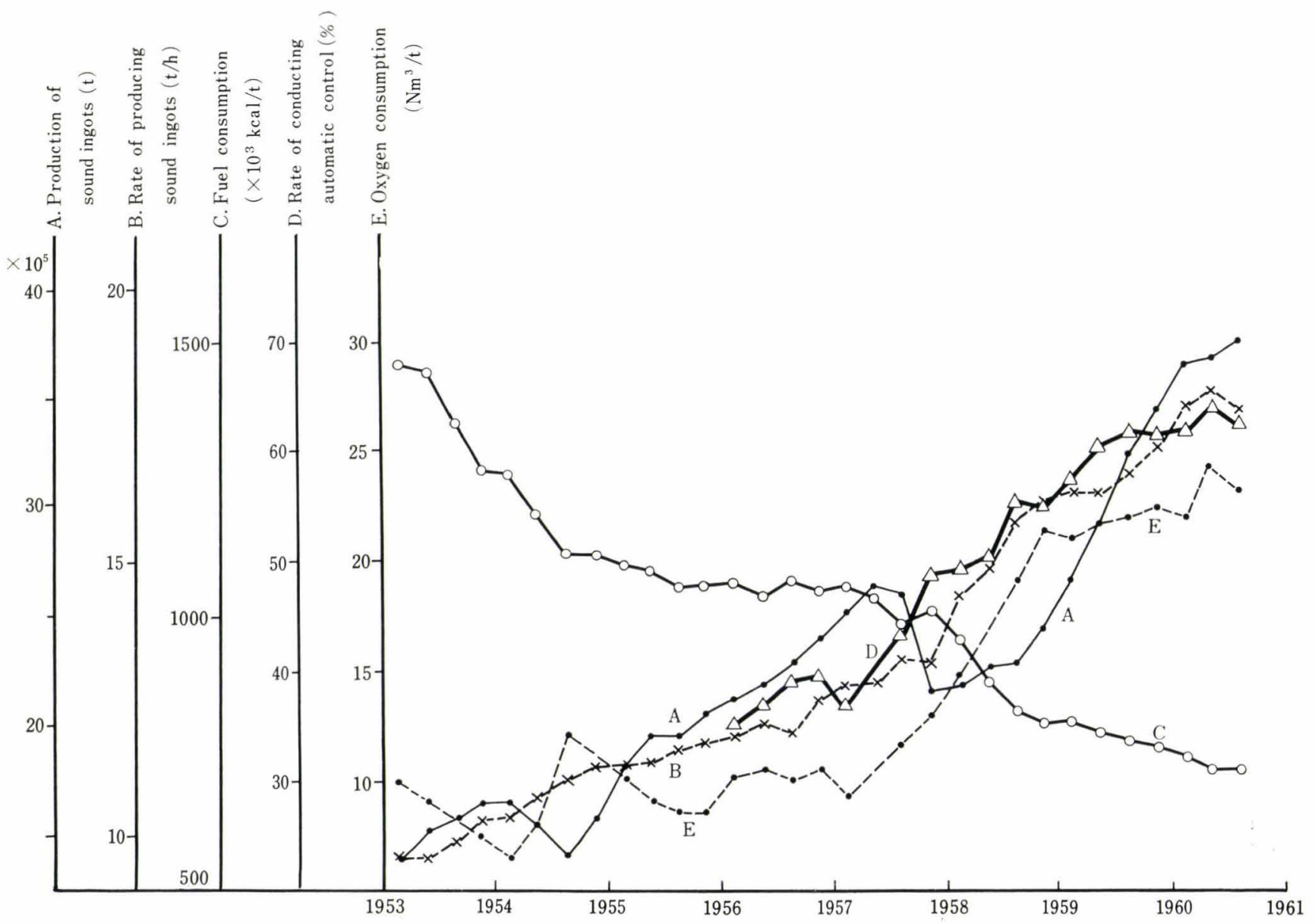

Fig. 4 Change of several factors relating to O.H. furnace operation in Japan

During such a long period it would seem that various improvements must have been made in the technique of steelmaking and equipment. Therefore, it is not proper to emphasize only the effect of automatic control. In some ten reports relating to automatic control presented by steel companies to the Instrumentation Division some remarkable results are mentioned.

As it seems that the increase in the use of oxygen has changed the techniques of steelmaking, the time to amend our view on automatic control has come. This subject will be discussed later.

\section{Research on Instrumentation and Control of Blast Furnaces}

The direction of research on instrumentation and control of blast furnaces is divided into the following two categories-stabilization of operation and instrumentation technique-in order to indicate furnace conditions. For instance, several types of automatic control of blast belong to the former, while research on continuous analysis of blast furnace gas and on continuous measurement of the temperature of tapped molten iron belong to the latter.

\section{Automatic Control of Blast}

Automatic control of flow and temperature of blast has been in operation in many blast furnaces for a fairly long time. Recently research on the quality of blast, that is, control of humidity and of oxygen quantity in blast, has been conducted and it has been put into practical use in many blast furnaces.

The number of iron works using a flowmeter with which temperature and pressure of blast flow can be compensated automatically in place of the conventional flowmeter in which only an orifice is used has been increased. Also research on the 
automatic control of distribution of blast flow at each tuyere through which hot blast is uniformly blown into a blast furnace has also been in progress.

Automatic control to make humidity in blast uniform is one of the recent interesting subjects, and this shall be described next.

\section{Control of Humidity in Blast}

In measurement of humidity in blast, the electric dry and wet bulb type and "Dewcel," which consists of a lithium chloride solution, are in practical use. A humidity transmitter is shown in Fig. 5.

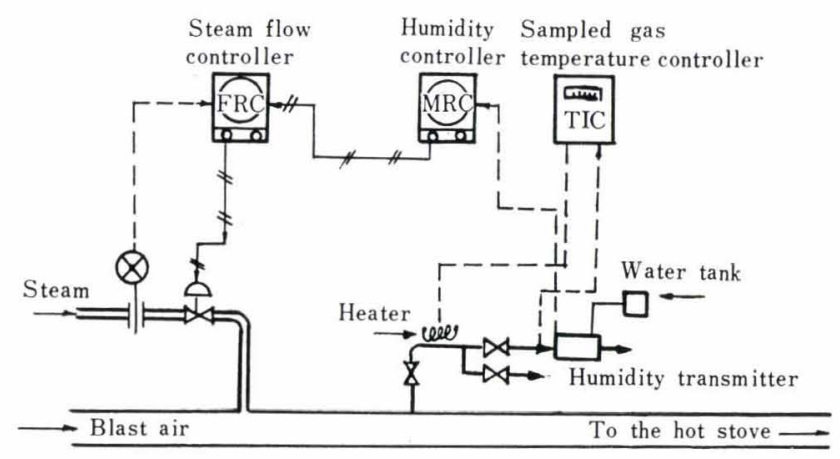

Fig. 5 Flow diagram of controlling humidity in the blast for a blast furnace

This transmitter has the function of separating one part of the blast, measuring its humidity, then sending a signal to a humidity controller, MRC. The humidity controller sends a signal to a steamflow controller, FRC, depending on the humidity, regulates the quantity of steam to be blown into blast, and keeps humidity constant. This system is the automatic control of humidity in blast.

Fig. 6 shows one example of control results. Irrespective of a sharp change of humidity in the

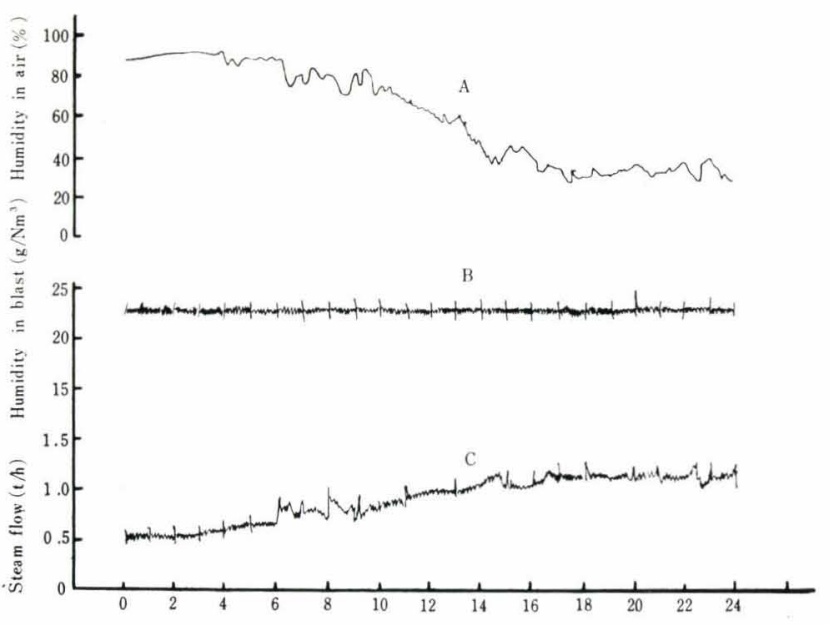

Fig. 6 One example of controlling humidity in the blast for a blast furnace air, humidity in blast supplemented by steam is kept constant with only a slight change below $\pm 5 \mathrm{mg} / \mathrm{Nm}^{3}$.

\section{Continuous Analysis of Blast Furnace Gas}

A continuous analyzer of blast furnace gas has been developed in order to analyze the process characteristic of blast furnaces and to determine furnace conditions. Tests were made by using several types of analyzers.

(a) Cambridge-type blast-furnace gas analyzers used at the Kamaishi Works of Fuji Iron \& Steel Co. and at the Kawasaki Works of Japan Steel \& Tube Corp. have required considerable labor for maintenance.

(b) Moxo-type duplex automatic analyzer, used at Kobe Steel Works has shown high accuracy and is comparatively easy to maintain.

(c) Infrared gas analyzer used at the Muroran Works of Fuji Iron \& Steel Co. has shown comparatively good results.

\section{Continuous Measurement of Molten Iron Temperature}

The temperature of molten pig iron was hitherto measured by an optical pyrometer or a radiation pyrometer. Considerable error was often found in this way of measurement and reliable accuracy actually could not be obtained. Measurement of molten iron temperature was conducted with accuracy by immersing a thermocouple into it in the same way as in the case of the immersion pyrometer which was developed for the purpose of measuring molten steel temperature in an open hearth furnace or a converter. Continuous measurement of the temperature of molten pig iron during tapping for about sixty minutes by using a special protective tube has become possible.

\section{New Thickness Gauge for Industrial Use}

In the field of rolling, above all instrumentation, laying stress on the heating furnace has hitherto been accomplished, but recently an instrumentation technique has been introduced into the rolling process itself. The thickness gauge for industrial use is one of the most important of the new instruments.

The recent remarkable rise in the rolling speed of rolling mills has brought about severe requirements in the field of control. It is no wonder that sufficient capacity cannot be achieved even with a rolling mill of high efficiency, if the size of the product cannot be measured correctly and controlled in the rolling process.

The following conditions, therefore, are required for the thickness gauge or the width gauge for industrial use:

(1) It requires possession of such response 
that the thickness or the width of products may be measured even at the highest speed of the rolling operation.

(2) It requires possession of accuracy sufficient for obtaining products with properties desired and its accuracy must be kept constant.

(3) It requires serviceability even under adverse conditions without any trouble.

In order to satisfy these requirements, noncontact type measurement is needed. In the recent high-speed rolling mill a non-contact type thickness gauge utilizing $\mathrm{X}$-ray or a radio isotope has been used.

Comparison of thickness gauges in which X-ray and a radio isotope are used respectively is shown in Table 1.

Table 1. Comparison of thickness gauges for plate using $\mathrm{X}$-ray and a radio isotope, respectively

$$
\text { X-ray }
$$

\begin{tabular}{|c|c|c|}
\hline $\begin{array}{l}\text { Limits of measurable } \\
\text { thickness } \\
\text { (ratio of maximum } \\
\text { thickness to mini- } \\
\text { mum thickness) }\end{array}$ & $\begin{array}{l}\text { Up to } 50 \mathrm{~mm} \\
(100: 1)\end{array}$ & $\begin{array}{l}\text { Beta-ray ...... } \\
\text { up to } 1.3 \mathrm{~mm} \\
\text { Gamma-ray ...... } \\
\text { up to } 60 \mathrm{~mm} \\
\text { (with a kind of RI } \ldots \ldots \\
10: 1 \text { ) }\end{array}$ \\
\hline Construction & $\begin{array}{l}\text { Complex and large } \\
\text { sized }\end{array}$ & $\begin{array}{l}\text { Small sized, but re- } \\
\text { quires consideration } \\
\text { for prevention of } \\
\text { trouble caused by } \\
\text { radiation }\end{array}$ \\
\hline Response speed & Speedy & $\begin{array}{l}\text { Somewhat inferior to } \\
\text { X-ray }\end{array}$ \\
\hline Accuracy & $\begin{array}{l}\text { Better than RI } \\
\text { Example: } \\
\text { Cold rolled } \\
\text { below } \pm 3-6 \mu \\
0.2-3.2 \mathrm{~mm} \\
\text { in thickness } \\
\text { Hot rolled } \\
\text { below } \pm 0.6-1.0 \% \\
10 \mathrm{~mm} \text { in thickness }\end{array}$ & $\begin{array}{l}\text { Example: } \\
\text { Cold rolled } \\
\text { below } \pm 0.1 \mathrm{~mm} \\
\begin{aligned} 4-10 \mathrm{~mm} \\
\text { in thickness }\end{aligned} \\
\text { below } \pm 1 \% \\
10-32 \mathrm{~mm} \\
\text { in thickness }\end{array}$ \\
\hline
\end{tabular}

Calibration

Calibration is made every $4-8$ hours

Whether an X-ray type or an RI type should be selected is dependent upon the conditions of its use, but it can be said that each of them generally satisfies the requirements of operation.

Most thickness gauges which are now being used in the iron and steel works of Japan are foreignmade, but recently home products have begun to be developed for practical use. There remain such important research projects as those on automatic measurement of the width or the length of products and on automatic control of rolling mills.

\section{Centralized Control and Utilization of Data Logger}

As one of the recent topics in the instrument industry, a data logger is taken up for discussion.
The data logger has a construction which shows measured variables in digital form in place of an analog-type instrument heretofore used, which is composed of graduation and indication. It is so contrived that an automatic typewriter will type many measured variables in digital form into a table in the form of a daily report in place of arranging many instruments on the panel. Therefore it will be very useful for the development of instrumentation techniques because of its ease in the collection and analysis of data, suitability for centralized control of operations and usability in combination with an electronic computer.

Each iron and steel works has paid early attention to the application of the data logger, but it appears that they could not use it easily because considerable change was expected in the phase of equipment, operation and control. However, several works have already been equipped with data loggers and they will amount to a considerable number if those under consideration are added.

In the Instrumentation Division, this problem was taken up under the theme "Centralized Control" and has been put into an earnest discussion. As an example, activities of the data logger in the energy center of the Tobata Works of Yawata Iron \& Steel Co. shall be introduced next.

This Energy Center was established for the purpose of carrying out collectively the distribution of demand and supply of such energies as fuel and electric power which are consumed in the works. Objects of control are electric power, blast furnace gas, coke oven gas, steam, oxygen, nitrogen and hydrogen.

The flow diagram of these objects is drawn on the panel, onto which are fitted signal lights, and indicators which indicate quantity of gas produced, quantity of gas used in large amount, gas holder level, flow in main pipe, quantity of electric power received and quantity of generated electric power. This makes a concentrative grasp of present conditions and collective instructions possible.

On the other hand, the data logger grasps quantities (total 46) of electric power (10), gas (20), steam (8) and oxygen nitrogen hydrogen (8) which are sent by a telemeter from various places in the works to this energy center. Reckoned value and mean value of the quantities generated, quantities used and quantities given and received to and from other areas are combined into a table at intervals of certain time by an automatic typewriter. In addition, the data logger has the function of watching, indicating off-normal part at once and giving warning.

The data logger has been used for drawing up a daily report of the blast furnace operation and for indicating the quantity of coke charged on a 
table and is expected to be used as an accumulator of data on the quality of products at the strip mill or the galvanizing line.

On the other hand, application of a computing logger has been proposed. This computing logger aims at analyzing characteristics of processes as the first step to computer control which it is thought will show one big course of control technique in the future. Also application to the processes of ironmaking, sintering and steelmaking is going to be examined.

\section{Activities of the Weighing Subcommittee}

As it is not long since the Weighing Subcommittee was organized, only five meetings have been held. Therefore, scarcely any definite result has been obtained.

In the iron and steel works, weighty solid substances such as raw materials and steel products are handled, so that the weighing machine can be said to be one of the most important instruments.

With the recent remarkable progress in iron and steelmaking techniques, a speed-up and improvement of accuracy in weighing have been required, and construction and capacities of weighing machines have shown a remarkable change.

Problems taken up in the Weighing Subcommittee in the past and subjects to be discussed in the future shall be introduced here in brief.

\section{Weighing and Unloading Raw Materials}

In Japan presumably the cost of raw materials occupies about $65 \%$ of the prime cost of steel products. Among the raw materials, 90\% of iron ore and $50 \%$ of coal being dependent on importation from abroad, it may well be said that the greater part of the raw materials is unloaded from ships. Therefore, confirmation of the quantity of raw materials unloaded is important.

As for a foreign freighter, the quantity of raw materials to be unloaded is customarily settled by a draught survey by shippers, but its reliability may sometimes be doubtful, so that a more accurate method of weighing is required.

\section{Weighing of Raw Materials to Be Charged into Blast Furnaces}

Composition of molten pig iron is decided directly by the accuracy in blending materials to be charged into blast furnaces. Some of the raw material often sticks in hoppers and is hard to release, so it is not easy to weigh each material delivered from various districts skillfully in a short time. Improvements in weighing system and accuracy and decrease of trouble have become the subject of discussions. A system which automati- cally weighs raw materials, by their producing. districts, to be charged into blast furnaces has also been tried.

\section{Weighing of Materials for Steelmaking}

In the steelmaking field, molten pig iron, steel scrap and ingot are the main objects to be weighed. Molten pig iron has been weighed with a weighing machine for molten iron transporting cars or with a weighing machine for cranes. Recently the latter, by which the net weight can readily be found has been widely used even though its accuracy is somewhat inferior to the former.

\section{Electronic Weighing Machine}

Users of electronic weighing machines have increased in number, because of the convenience in their construction. But as these are inferior in accuracy to the weighing machines heretofore used, application has become the subject of discussion.

\section{Unification of Words used by Weighers}

As there are various words in Japanese for weighing machines and this causes inconvenience, unification of these words has been examined.

\section{Inspection and Maintenance of the Weighing Machine}

With the advancement of weighing machine in shape and construction, as with other industrial instruments, the method of inspection and maintenance has come to the frorit.

\section{Others}

Other items discussed in meeting of the Weighing Subcommittee are as follows:

(a) Improvement of the record-integrating system

(b) Effective use of the conveyor scale

(c) Control of net weight

(d) Recognition of accuracy

(e) Education of workers concerned

\section{Conclusion}

The above is the general view of instrumentation in Japan. The Instrumentation Division, reflecting the remarkable progress of instrumentation techniques, has gradually become prosperous, and active discussion has been developed on many subjects. 